\title{
Sustainability of Informal Shuttle Transport in the City of Harare
}

\author{
Shakerod Munuhwa*, Tendai Silvaziso Mandere, Ephraim Govere, King Christopher Muchenje \\ Business Management Department, BAISAGO University, Bag 149, Gaborone, Botswana. \\ *E-mail: shakerodm@gmail.com
}

\begin{abstract}
This study sought to investigate the sustainability of informal shuttle transport in the city of Harare. Traditionally, the provision of public transport is considered to be government's responsibility. Due to lack of economic growth, rapid rise in urban population, and declining standards of living, government-provided public transport is often inadequate; it is the privately operated public transport modes that cater to the mobility needs of the population. Informal shuttle transport refers to small illegal vehicles that play part of taxes ferrying passengers within the city. These small vehicles do not follow most road traffic regulations but are always there when city people need transport and are a faster mode of urban transport. This informal shuttle passenger transport sector, however, is not sufficiently acknowledged due to a number of reasons including lack of proper passenger transport regulation, lack of road safety, highly polluting and a cause of traffic congestion. This paper unpacks challenges posed with informal public transport particularly those providing shuttle services within the central business district (CBD) of Harare. The paper then examines and recommends various strategies that can make such operators contribute to achieving sustainable urban transport system. Data was collected through unstructured interviews from key stakeholders in both private and public sector basically examining the relationship between the increase in informal shuttle transport and transport sustainability. Stakeholders agreed on the need to improve transport in Harare and proffered solutions which included mass transit, crafting of a policy framework to formalise informal shuttle transport operators, need for infrastructure improvements, institutional capacity and good governance among others.
\end{abstract}

Key words: informal shuttle transport, congestion, sustainability, central business district, Harare, economic growth

DOI: $10.7176 / \mathrm{JESD} / 11-8-14$

Publication date: April $30^{\text {th }} 2020$

\subsection{Introduction}

Informal public transport exists in almost every part of this world. Cities of the developed world also have informal transport services reference being the Brooklyn borough of New York City, informal operators run a paratransit system along some busiest thorough fares, (Cervero, 2015). Operated mostly by recent immigrants from the Caribbean, and for recent immigrants from the Caribbean, these unlicensed operations compete directly with municipal bus services. The vehicle of choice, utility vans, ply the main corridors of Brooklyn, taking passengers from anywhere along the route for a flat fee. Some operators go into Manhattan for a premium fare. Drivers also diverge from standard routes to avoid congestion, or to provide front-door delivery again for a fare premium (Kumar and Barrett 2013).

In Hong Kong, informal vehicle operators began circulating illegally in the 1960s (Lee 2013). They were neither licensed nor insured for transit operations and competed directly with other formal transit services. A strike by formal transit workers in 1967 brought the informal operators into consideration by regulators as a useful component of a comprehensive transit system. The minibus system has since been "formalized" through a set of rules, allowing the operators to purchase licences for operation and undergo inspections (Lee 2013). The large and mostly impoverished populations of African cities are dependent on public transport to provide them with accessibility and mobility. Public transport is not just a social good or an alternative to private car travel, but it is the only motorised mode available to the vast majority of the urban population in most African cities (Shittu 2014).

Sustainable transportation in Africa means "subsidy-free, but affordable public transport for almost all". That already comprises two parts of the sustainability triangle: the economic and social one. (Katz, 2009). There are already initiatives that start replacing informal public transport with formal public transport where huge capacities are needed and that try to reorder the informal public transport in order to supply services to these big corridors. The ecological part has to be addressed as well, for example in the form of rules that improve the technological level of public transport. The most famous example for this is the state of the vehicles used by informal operators. 
The average ages of these fleets often lie clearly above 20 years. Regulations regarding security standards and emissions could probably solve this problem, if they are well enforced. (Katz 2009).

Golub ,(2013), expounded that sustainability right now is not primarily about the ecological part, but rather about the functional, economic and social issues of transport. People on the street, making their daily transport decisions especially in Africa are normally not being environmentally conscious in that decision. They are thinking about how they can get from A to B as fast, as cheap and as convenient as possible, (Katz 2009). The problem with public transport planning in most African cities is that public transport is either poorly planned or not planned at all (Mfinanga, 2014). There is a lack of adequate information and planning framework to guide decision makers, resulting in many cities either selecting inappropriate systems based on those used in developed countries or letting private operators decide. (Golub 2013) asserts that developing countries have different economic and social conditions from those in developed countries and solutions, specific to their own needs as opposed to simply copying approaches used by developed countries, should be developed and applied in each country.

Many cities allow small operators to operate without hindrance, and in some of the poorest cities of sub-Saharan Africa, small operators provide all mass transport services. Technically, informal services are those operating without official endorsement (Kumar and Barrett 2013). Usually this means vehicles and operators do not have appropriate licenses, permits, or registration papers from public authorities to provide collective-ride services to the general public. The absence of official endorsement also means that most do not meet driver or vehicle fitness standards and are not properly insured or indemnified. The informal transport sector is generally made up of smallsized vehicles, owned and operated (or leased) by a single individual. Most drivers are low-skilled younger men who migrated to cities from the country side (Luthra 2016). Informal transport vehicles are often low-performing and old. The informal sector almost always delivers paratransit-type services, meaning services are either door-todoor or flexible enough to deviate from standard routes (Golub 2013). Pricing is similarly flexible. Many times informal services operate in a laissez-faire environment, prompting operators who survive on low profit margins to actively, and sometimes dangerously, compete for customers. This gets expressed as stopping almost anywhere to board passengers, overloaded vehicles, and unsafe driving habits, what economists call " collectively damaging.

In this same vein, operators often "cream-skim' 'offering frequent services at peak times and in peak directions, while leaving off-peak riders waiting until vehicles fill, sometimes for an hour or more (Cervero 2015). South Africa represents the extreme of how ruthless and deadly unregulated competition can be in the illegal paratransit world. There, rival cartels that control thousands of low-cost minibuses, or "combis", fight over the most lucrative routes. There, sadly but almost literally "cutthroat competition" has taken its toll. During the 2013s, more than 2011 people died as a result of paratransit-related violence, according to official statistics. (Cevero 2015).

In the Zimbabwean case informal public transport has emerged through three ways, first by the introduction of the Economic Structural Adjustment Program ESAP (Government of Zimbabwe 2011) which liberalised the economy bringing in a lot of commuter omnibuses that put so many conventional buses out of business. In essence, the main objective of ESAP was to liberalise the economy. This culminated in the deregulation of urban passenger transport in 2003 when privately operated public transport vehicles were for the first time legally permitted to operate in urban areas (Maunder and Mbara 2015). Privately operated vehicles in the form of minibuses (officially known as commuter omnibuses in Zimbabwe) have mushroomed and now dominate the entire public transport market in Harare resulting in the dearth of the conventional bus operator.

Peugeot station wagon vehicles with a seating capacity of seven passengers (although 10 was the norm) were legally licensed to provide a shared taxi service on set routes, (Maunder \& Mbara 2015). The above measures marked a watershed in the decline of conventional public transport in Harare. In addition, some operators (illegal and informal) have taken advantage of unmet demand and are plying on short routes. These small cars and minibuses park willy-nilly blocking other traffic and causing congestion. In Harare, akin to many cities of developing countries, the experience has been that Government agencies are unable to provide adequate formal public transport. An informal public transport system has emerged to cater for the mobility needs unmet or partially met by formal public transport systems (Golub 2013). Informal transport relies more heavily than the formal sector on traditional knowledge and resources, family labour and ownership, small-scale operations and labour-intensive techniques, and offers low barriers to entry for potential participants, (Rakowski 2014). There is an influx of informal public transport coming from commuter omnibuses and small vans that are playing the role of public transport in the nations and cities. A socially sustainable public transport system provides accessibility, mobility and equity of transport movement in a friendly and efficient manner from one point to the other which these omnibuses and small vans may not meet. (Miralles 2011; Rodrigue 2017) pointed out, the social times (mobility times) of the city "draw the everyday spaces of the metropolitan regions" (p. 127). Travelling time contributes enormously to the citizens' view of the quality of the public services provided and, therefore, the quality of their 
everyday life. Time is a measurement that relates activities to places (May and Thrift 2011; Davouidi 2017). However due to the inability of formal public transporters to meet the demand of ever increasing population, there has been an emergence of the informal public transporters which are somehow not efficient, does not provide quality service and usually pose the public to a myriad of social and safety risks. The study seeks to make a critical assessment of informal public transport so that necessary options and recommendations can be employed to improve public transport operation and social equity of passengers in Zimbabwe. This study will be the first of its kind to explore an area where little is known. This study seeks to assess sustainability of informal shuttle transport in the City of Harare. The following research objectives guided this study:

i. To establish the causes of the emergence of informal public transportation in the city of Harare.

ii. To critically assess if the informal public transport meets social sustainability of people in Zimbabwe.

iii. To find out reasons why informal public transport continue to exist alongside the formal public transport.

iv. To establish the relationship between an increase in informal shuttle transport and sustainable operating practices.

\subsection{Literature Review}

\subsection{Transport}

There is no single definition of transport as it is both a physical and a relative phenomenon (Rahane \& Saharkar, 2014). Traditionally, the provision of public transport is considered to be government's responsibility. Due to resource and capacity constraints in developing countries, however, government-provided public transport is often inadequate; as the privately operated public transport modes like mushikashika (Zimbabwean name), shared autorickshaws, mini-buses, unregistered pirate taxes that cater to the mobility needs of the population ( Kumar 2013) This sector, however, is not sufficiently acknowledged for the important contribution that it makes towards mobility supply, in terms of both policymaking and city planning exercises. In addition, government authorities typically perceive these modes as unsafe, highly-polluting and a cause of traffic congestion as there is a complete absence of research and knowledge on these modes (Mbara and Chandra, 2015).

\subsection{The causes of the emergence of informal public transportation in Zimbabwe}

There are a number of specific circumstances, which causes the emergence of informal public transportation in Zimbabwe such as patterns, income levels, car ownership trend, infrastructure investment, regional economic dynamics, and tourism, poor land use integration among other factors.

\subsection{The emergence of informal public transport}

Rapid urbanization in developing countries has led to an unprecedented increase in demand for mobility services, which in turn has put tremendous pressure on urban transport infrastructure and services. Increase in supply of public transport services, in particular, has been slow and has failed to meet the mobility needs of the urban population due to several fiscal and institutional constraints (Khayesi 2009). Even in cities where public transport is available, formal public transport services are often inadequate and unreliable, giving rise to the population's dependence on personal mobility options and informal public transport services for meeting their mobility needs. Informal public transport services, as the term suggests, refer to public transport services that are provided differently as compared to the typical government-provided bus- and rail-based transport in cities (Vassileva 2016). Existing mostly in the form of shared services, informal transport modes use vehicles with seating capacity ranging from 3 to 20 people. These services are usually provided by private-sector entities, some of which do not comply with the government rules and regulations. The term is often used to refer to all public transport services that are not provided by government agencies the informality of each system in terms of compliance with regulations on vehicle manufacturing and operations, however, could vary from mode to mode and city to city (Gunay 2017).

\subsection{Positive contributions of Informal Public Transport}

The informal transport sector provides real and meaningful benefits to significant segments of populations of many third world cities. According to (Vassileva 2016), the chief benefit of informal transport is that it provides much needed and much valued mobility, especially for the poor. Ninety nine out of a hundred households in the poorest countries of Africa do not own or have access to a private automobile, thus they are entirely dependent on public transport for reaching jobs, markets, medical clinics, and other destinations. Women make up the majority of 
customers. Where bus and metro services are irregular, unreliable, or non-existent, informal transport operators provide indispensable services. Private jitneys and mini vans often ply routes and enter neighbourhoods that are inaccessible by buses (Khayesi 2009). Many navigate along heavily pocked and rutted roads of the city.

During periods of heavy rains, pedicabs can negotiate roads and alleyways that are impassable by motorized means. The important role in connecting poor neighbourhoods to job centres is often under appreciated. In the world's biggest cities, motorcycles, pedicabs, jitneys, and vans enable tens of thousands of custodians, chambermaids, sweat shop and assembly line workers, and day labourers to reach their jobs each day. During night shifts, when buses are no longer running, they sometimes are the only means of getting around. Low skilled labour is absolutely vital in providing the maintenance, service, and production inputs necessary to sustain a rapidly industrializing economy (Wilkinson 2018). Enhanced mobility increases the transitive space of a metropolitan area, enlarging the labour shed and providing access to enough potential workers so as to keep wages competitive in the global marketplace. Informal transport is often of greater value in delivering workers to the factories and mass assembly plants of the developing world than is realized. Even though informal carriers provide much valued mobility for the poor, the costs of atomized, uncoordinated services can quickly mount for many low skilled day labourers who are forced to live in informal housing settlements on the peripheries of the world's mega cities.

In many poor cities, informal shuttle transport comprises as much as 15 percent of total employment. The significant employment role played by informal transport is perhaps no surprise given that the transport sector accounts for around 15 percent of the gross domestic products of many industrialized nations. Critics question whether this form of livelihood is, on balance, socially productive. Ultimately, the marketplace is the mediator if enough customers are willing to pay enough for informal public transport operators to make ends meet, then society as a whole is better off. Problems only abound when there are excessive numbers of informal public transport operators. However, one might ask whether society would fare for the worst if many were forced out of the informal transport sector, left to fend for their own on the streets. Resulting increases in crime and illicit activities that are more harmful than informal transport might very well carry even higher social costs, (Wilkinson 2018). The current major concern is the way these informal transporters operate which is so risky to passenger life as shown in Figure 2.1.

\subsection{Negatives about Informal Public Transport}

Figure 2.1:Informal shuttle operators in Harare
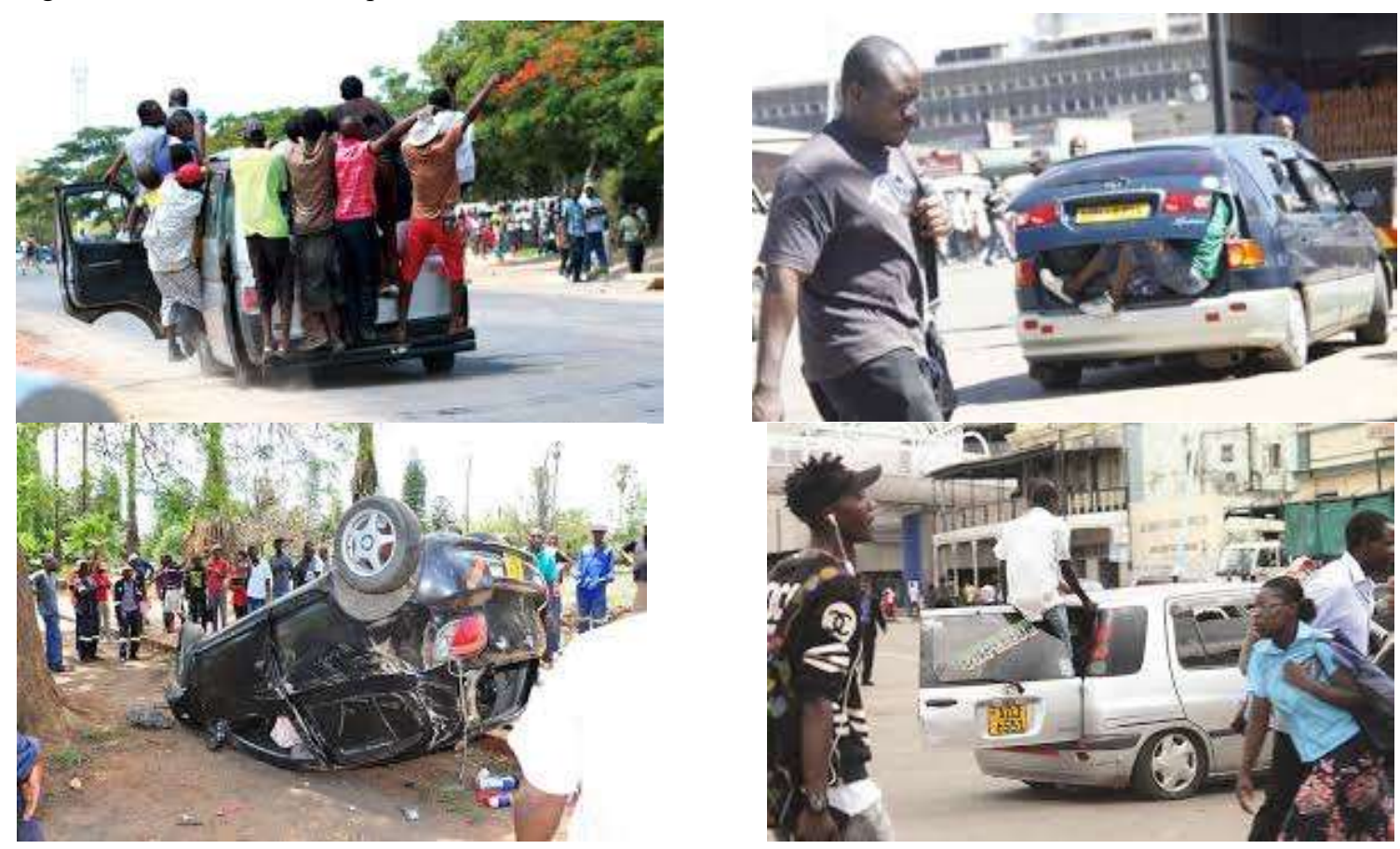

(Field survey: Harare urban 2020) 
Vehicle ownership patterns

The ownership patterns of informal public transport modes are highly fragmented, typically an operator would own and operate only a single vehicle. Cycle rickshaws are the only real exception where a single operator's fleet size was often as high as 100 to 150 vehicles. However, even among cycle rickshaw operators, instances of single operators owning large fleets were very rare (Khayesi 2009).

Fares

Informal public transport systems are operated by private individuals and operators. Providing transportation services is a business activity, which means that maximizing profit is the key objective of operating a vehicle. Although governments usually set the fares for both personal-hire and shared services, the majority of the drivers surveyed charged passengers at their own discretion (Sclar 2007). Personal-hire auto-rickshaws, which are required to charge passengers according to the fare meter, usually did not have meters installed on their vehicles. Driver groups or unions operating shared services on the same routes usually decided the fare to be charged. In addition to the drivers' and operators' profit-seeking motivations, a lack of timely fare revisions by government authorities was another root cause of over-charging by drivers (Fazio 1999).

Compliance with safety standards

(Gunay 2007) alluded that to understand the issues related to the safety of informal public transport modes, factors like vehicle design, overloading, capacity utilization, and physical infrastructure will be looked at. Due to the absence of adequate rule enforcement, the operators of informal transport modes often retrofit their vehicles to carry more passengers than the manufacturers originally intended the vehicles to hold. Typical retrofits are additional seats in the driver, passenger, and luggage compartments of the vehicle and additional handrails and footboards. These modifications are made with the sole aim of increasing the passenger-carrying capacity of the mode and thereby increasing the profitability of operations. As the vehicles are not tested after retrofitting, there is no way of knowing whether they are roadworthy from the perspective of road accidents. Poor vehicle design and precarious road conditions rendered these modes highly vulnerable to road accidents, posing a high risk of injury to the on board passengers (Khayesi 2009). As shown in figure 1 it is evident that the images of informal shuttle transport are reflecting a number of unsafe acts as they ferry passengers from one point to the other.

Overloading and capacity utilization

High levels of demand for transport services, coupled with inadequate rule enforcement and the profit-making motives of operators, make overloading a common practice in informal modes. The phenomenon of overloading was found to be prevalent across most cities of in Zimbabwe (Mbara and Chandra 2015). A comparison of the designed seating capacity of the vehicles with the average number of passengers carried per trip indicates overloading on all modes. On average, informal public transport modes are found to be carrying twice as many passengers as the designed seating capacity of the corresponding vehicles. The capacity utilization rates of informal transport modes also offer evidence of overloading (Fazion 1999), the same is shown in figure 2.1.

Physical infrastructure availability

Not only do these modes demonstrate intense usage levels, but most of the vehicles also operate without the benefit of any dedicated supporting physical infrastructure such as official pick-up/drop-off stops. In the absence of designated stands and stops, the vehicles pick up and drop off passengers at the convenience of the passengers (Mbara 2014).

\section{Safety of passengers}

While factors such as vehicle design, overloading, high usage rates, and a lack of adequate physical infrastructure appear to compromise the safety of both passengers and drivers of informal public transport modes, there are not enough statistics on road accident to comment specifically on the safety of the modes. Note has been taken that despite the overloading and retrofitting practices, informal public transport modes are safer compared to other formal modes of transport. In 2013, only 6\% of all accidents in Harare were caused by informal modes (Mbara and Chandra 2015). The low accident rate among informal modes could be attributed to their slow operating speeds, which are caused by overloading and frequent stops.

Environmental performance

Environmental concerns such as high levels of pollution and congestion are often cited as reasons for restricting the use of informal public transport modes or altogether banning them from operating in the cities. Observers usually assume that operators of informal public transport modes not only overload their vehicles but also employ 
older vehicles and resort to fuel adulteration, all in hopes of turning better profits. All these factors can significantly affect the environmental performance of these vehicles (Mbara and Chandra 2015).

\subsection{Theories of informal shuttle transport}

\subsubsection{Urban travel demand model}

Travel Demand Management, or TDM, is a general term for strategies that increase overall system efficiency by encouraging a shift from single-occupant vehicle (SOV) trips to non-SOV modes, or shifting auto trips out of peak periods, (Wilkinson, 2008) This supports the Urban Mobility Plan's focus on moving people and goods rather than motor vehicles. TDM seeks to reduce auto trips and hopefully vehicle miles travelled by increasing travel options, by providing incentives and information to encourage and help individuals modify their travel behaviour, or by reducing the physical need to travel through transportation-efficient land uses, (Wilkinson, 2008). The cumulative impact of a comprehensive set of TDM strategies can have a significant impact on travel behavior, system efficiency, and SOV rates. TDM programs are usually implemented by public agencies, employers, or via public private partnerships, (Metro, 2015)

- The achievement of sustainable urban transport cannot be accomplished without implementing some TDM measures. Demand Management is a technique that uses various strategies to increase transportation system efficiency (Victoria Transport Policy Institute, 2011). In essence, TDM measures are concerned with the alteration of travel behavior in order to enhance the efficient use of the existing road infrastructure and facilities. Even assuming that the city has the requisite funds, any attempts to match the demand for road space with supply are untenable, as more traffic would be generated clogging the new road space provided and compounding the congestion and pollution problems, (Metro, 2015).

Traffic flow can be improved by shifting the trip in terms of the use of alternative times through measures such as staggered working hours or use of mass transit vehicles that are able to ferry a large number of passengers at a time. (Mbara 2014). A reduction on car dependence trips is necessary in order to minimize the need for these informal transport operators in urban areas. This can be achieved by encouraging people to share their cars. A significant shift to public transport would also reduce trips but this has to be concomitantly undertaken with the improvement of public transport in terms of adequacy, efficiency and reliability, (Mbara ,2014). Transport and travel demand therefore can only be minimized when the city authorities introduce mass transit vehicles. Informal shuttle transport in this regard may not be such solution since they only ferry a few passengers at a time. Demand for such vehicles is so high and they contribute towards so much externalities such as air pollution, congestion and noise pollution, (Mbara,2014).

\subsubsection{Sustainable transport theory}

Figure 2.2: Sustainable Transport goals

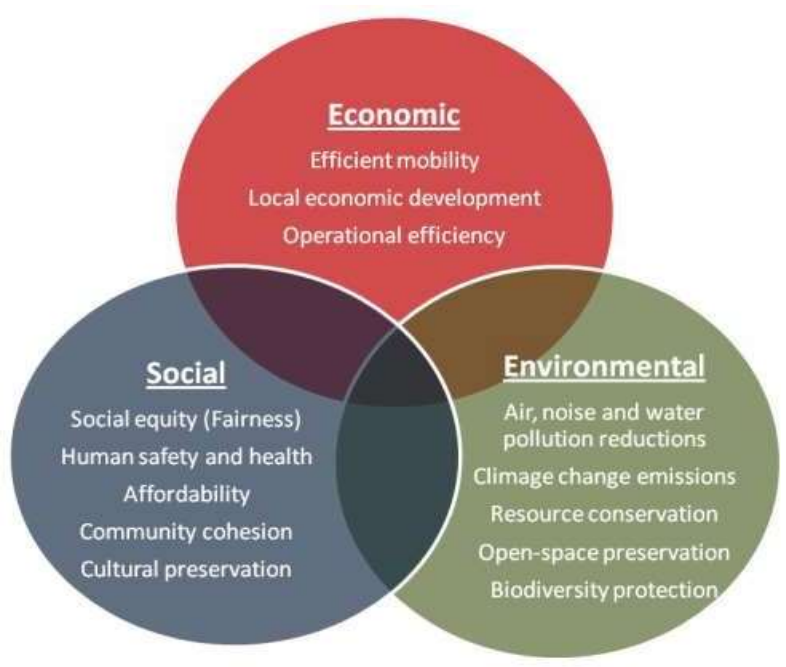

(Authors,2020) 
According to the framework of transport sustainability(Figure 2.2) passengers can choose from various modes, location and pricing options, particularly ones that are affordable, healthy, efficient, and accommodate non-drivers, Cervero,2015).The various components of the transport system are well integrated, such as pedestrian and cycling access to transit, and integrated transport and land use planning. Affordable transport options provide access to lower-income households. Resource (energy and land) efficiency policies encourage energy and land efficiency. Road, parking, insurance and fuel are priced to encourage efficiency, and facilities are managed to favour higher value trips and more efficient modes. Policies support compact, mixed, connected, multi-modal land use development in order to improve land use accessibility and transport options. Transport agencies, service providers and facilities are managed efficiently to minimize costs and maximize service quality. In relation to the sustainability goals in transport all passenger operators weather formal or informal should meet the three facets of sustainability,(Cervero,2015).

\section{Methodology}

\subsection{Research Design}

The exploratory research design was used for this study, which is not intended to provide conclusive evidence but to help in better understanding of a phenomenon. Exploratory research tends to tackle new problems on which little or no previous research has been done (Sarantakos, 2006).

\subsection{Sample size and sampling technique}

In this study, the sample size was 624 people for a population of 2.1 million Harare City residents, assuming a 95 per cent confidence interval and a margin of error of 5 per cent. (Sample size calculator by Raosoft, 2018).

In the survey part the male and female respondents had equal chances of taking part as random selection was used. Purposive sampling was adopted and seventy percent (80\%) of the population of the study was used as a sample for the research in question.

\subsection{Instruments}

Questionnaires, in-depth interviews (IDIs) and observational checklist were developed to collect primary data from the field. The questionnaire comprising a mix of open-ended and closed-ended was divided into two sections. Section A focused on the demographic characteristics of respondents such as gender, the level of education, occupation, etc. Section B centred on the causes of the emergence of informal public transportation in Zimbabwe, an assessment of the informal public transport meets social sustainability of people in Zimbabwe and reasons why informal public transport continue to exist alongside the formal public transport.

\subsection{Data collection procedures}

Qualitative research emphasized the importance of context in analysing data (Denzin \& Lincoln, 2015). During the research process and especially during the data collection phase, the participants were able to decide on the venue which they used for completion of questionnaires and interviews. As a result, each participant chose a venue which was convenient to him or her.

\subsection{Data analysis}

Quantitative data was analysed and presented using descriptive statistics, frequencies and percentages. Data were also analysed using correlations and multiple linear regressions. The Statistical Package for Social Sciences (SPSS) version 21 was used to process the data set. Qualitative data were transcribed, then categorized under specific themes and manually analysed.

\section{Results}

\subsection{Response rate}

The study represented a response rate of $80 \%$ which was sufficient for data analysis and conforms to previous research studies (Desbordes, 2016; Gaurav, 2017) who stipulated that a response rate of $80 \%$ and above is deemed excellent for a research study. The researcher managed to conduct all the interviews giving a $100 \%$ response rate. The response rate for interviews was high as appointments were made prior to the interview date. The response rate for interviews was high as appointments were made prior to the interview date. The respondents were helpful with information as they were willingly participated in interviews. 


\subsection{Gender}

During this study it was noted that $60 \%$ of the respondents were males whilst $40 \%$ were females. This shows that at there were more male than females. In a similar study which was conducted by Moyo (2017) he noted that there are more male due to the nature of duties in transport sector. Zimstat (2012a) in Makanyeza (2014) noted that there are more males $(51.94 \%)$ than females $(48.06 \%)$ in Zimbabwe. As a result, the findings which were attained in this research study were highly expected.

\subsection{Age group}

Respondents of this study who completed the questionnaire were asked to indicate their age group and their responses were captured down in table 4.1 and figure 4.1 .

Table 4.1: Age group of respondents

\begin{tabular}{|l|l|l|}
\hline & Frequency & Percent \\
\hline Below 30 & 125 & 20.0 \\
$31-40$ & 218 & 35.0 \\
$41-50$ & 156 & 25.0 \\
$51-60$ & 112 & 18.00 \\
60 and above & 12 & 2.00 \\
Total & 624 & 100.0 \\
\hline
\end{tabular}

Figure 4.1: Age of respondents

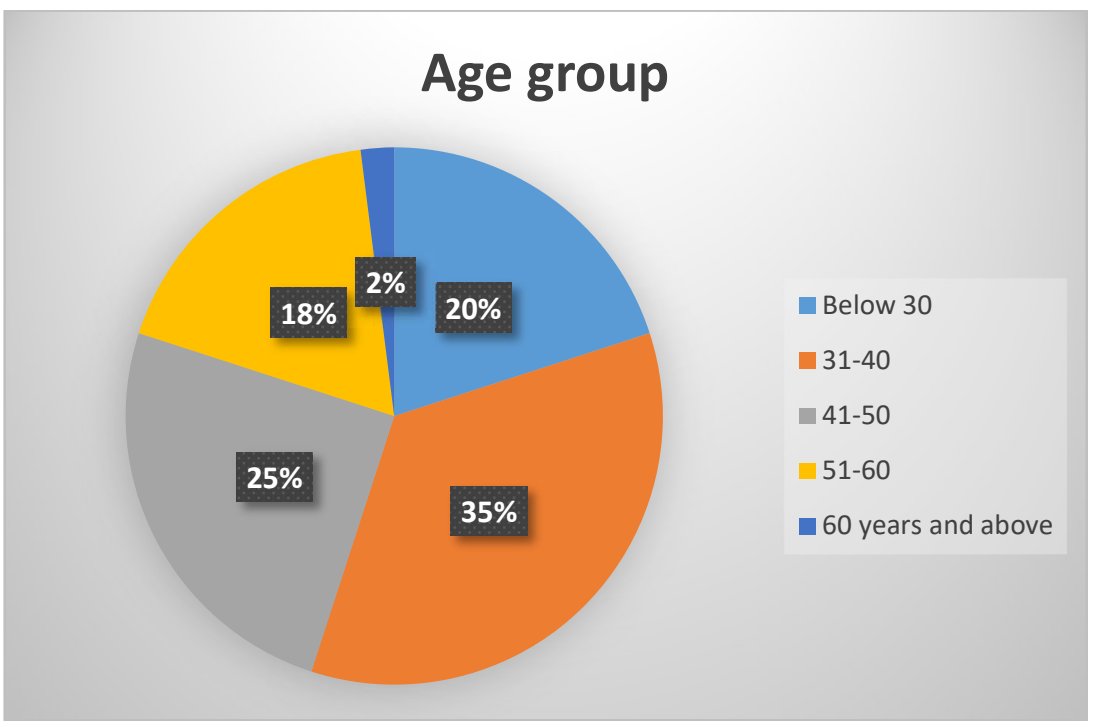

\section{Source: Survey}

Table 4.1 and figure 4.1 shows that $20 \%$ of the respondents had 30 years and below, $35 \%$ were in age range of 31 40 years, $25 \%$ were in the age range of $41-50$ years, $18 \%$ were in the age range of 51-60 years whilst $2 \%$ had 60 years and above. From the data obtained above it can be noted that the majority $35 \%$ were in the age range of 31 40 years. In a similar study conducted by Makanyeza (2014) he noted that there tend to be a fine balance in the age group of transport organizations in Zimbabwe hence the results attained in this research study were highly expected. Meanwhile, it can be concluded that the results attained in this research study where reliable as the majority of respondents were mature enough to provide honest and reliable answers on the impact customer relationship marketing on customer purchasing decision. 


\subsection{Highest level of education}

Respondents of this research study were asked to indicate their highest level of education and their responses were captured down in table 4.2 and figure 4.2 below.

Table 4.2: Highest level of education

\begin{tabular}{|l|l|l|}
\hline & Frequency & Percent \\
\hline Ordinary level & 75 & 12.0 \\
A level & 76 & 14.0 \\
Bachelor's degree & 250 & 40.0 \\
Diploma & 112 & $18 \%$ \\
Master degree & 37 & $6 \%$ \\
Phd & 25 & $4 \%$ \\
Other & 37 & $6 \%$ \\
Total & 624 & 100.0 \\
\hline
\end{tabular}

Figure 4.2: Highest level of academic qualifications

\section{Highest level of education}

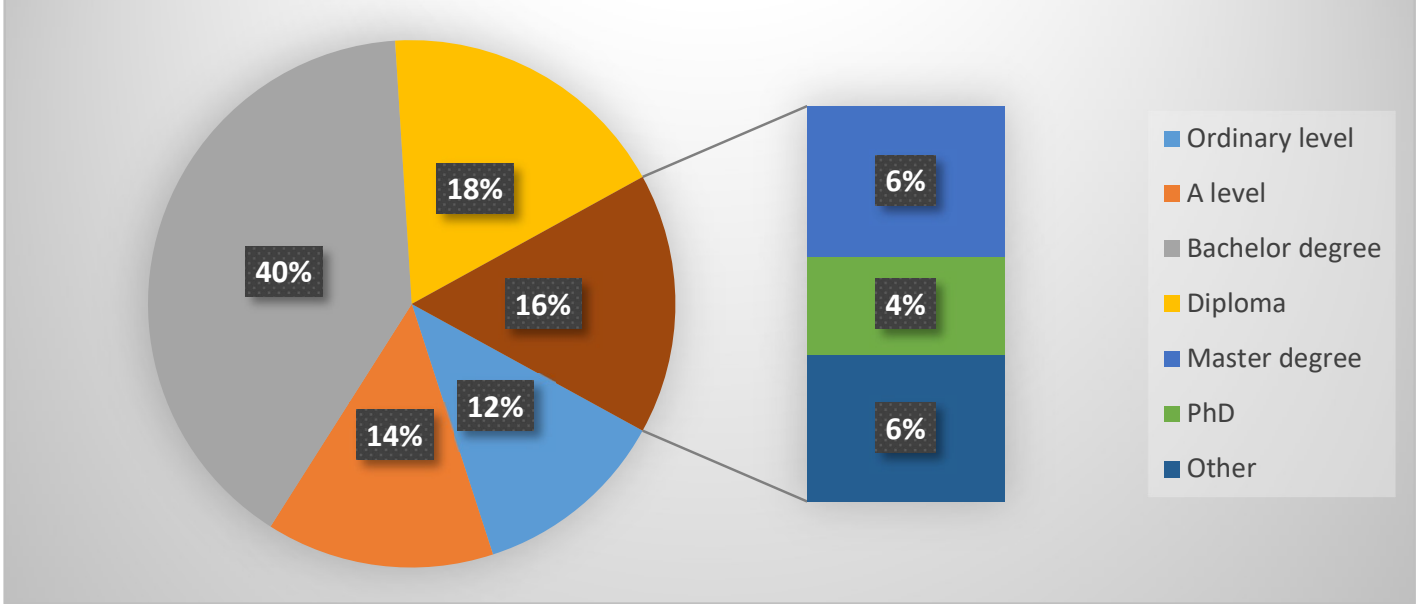

Source: (Survey 2020)

Figure 4.2 above shows that few respondents had doctoral degree $(4 \%)$ and a master degree $(6 \%)$ while a considerable number of respondents have attained a bachelor's degree (40\%) and a diploma (18\%). More so, few respondents have attained advanced level education (14\%), ordinary level education $(12 \%)$, other certificates such as ZJC and grade 7 were $6 \%$. This implies that the study sample mainly consists of educated consumers. This can be attributed to the general observation that the respondents who were more responsive to participate in the survey were those who appreciated Sustainability of Informal Shuttle Transport in the City of Harare perhaps because they would have done research somewhere especially at the tertiary education level.

More over from the figure 4.2 above it can be noted that the respondents had the capacity to answer all questions in the questionnaire as they were educated. Shiri (2017) also reckons that knowledge is needed. This is in support with the view that most of respondents who completed the questionnaire had a bachelor degree and they were able to interpret all the questions about sustainability of informal shuttle transport in the city of Harare. 
Table 4.3. Direction of the relationship between an increase in shuttle transport and the derived level of sustainability in the City of Harare .

\begin{tabular}{|l|l|l|l|}
\hline Chi-Square Tests & Value & Df & Asymp. Sig. (2-sided) \\
\hline Pearson Chi-Square & $66.079^{\mathrm{a}}$ & $\mathbf{4}$ & .000 \\
\hline N of Valid Cases & 624 & & \\
\hline a. 2 cells (20.0\%) have expected count less than 5. The minimum expected count is 3.45. \\
\hline & & Value & Approx. Sig. \\
\hline Ordinal by Ordinal & Gamma & -.655 & .000 \\
\hline N of Valid Cases & 624 & \\
\hline a. Not assuming the null hypothesis. & & \\
\hline $\begin{array}{l}\text { b. Using the asymptotic standard error assuming } \\
\text { the null hypothesis. }\end{array}$ \\
\hline
\end{tabular}

Table 4.3 above show that there is an association between increasing number of informal shuttle transport operators and the level of sustainability derived. Sustainability measurements involved adherence to environmental standards in traffic operations, healthy, safety, driver licence, vehicle comfort, vehicle roadworthiness, and compliance with all by laws with regards to road traffic act.Gamma -.655 shows a very strong negative relationship. The results show that as many players join informal shuttle transport levels of the transport operating system with regards to urban transportation becomes less sustainable. This implies that when more players are coming in then they are contributing more to unsustainable ways of operating urban passenger transport.

\subsection{Possible solutions to unsustainable informal urban transport in Harare}

A number of measures to improve sustainability in shuttle urban transport were proposed by the respondents: An informal operator responded that:

"There is high level of unemployment and for the past 3 years I couldn't find any job until I decided to use my small vehicle in shuttle transportation within the city. City of Harare and ministry of transport must have flexible requirements for one to become a registered shuttle or taxi operator. The amount of money they require A taxi driver(formal shuttle operator):

"The government and police need to intervene as soon as possible and remove these illegal operators who are everywhere eating our stake. We went through mandatory requirements for us to operate smoothly, yet after having done that ,informal operators are coming without complying with the law and take all the revenue. If the situation remains uncontrolled, formal operators are likely to go broke and get out of business. These informal players sometimes operate from any point of the city and charge very little prices which we can't afford as we have more overhead costs in terms of compliance."

A pedestrian stated:

"I mostly prefer mushikashika (informal shuttle transport) as they are convenient and we can also be able to negotiate rates. The only challenge is they are sometimes speeding, not very safe and they ferry too much people even in the boot. Given an option I think they just need to panel beat the way they operate and improve on safety and loading numbers.

A City of Harare - Transport planning Official: 
"We are working with municipal police and the Zimbabwe Republic Police to ensure sanity through removal of all informal and unregistered transport operators for now. Going forward we are planning to invite these operators and have a working plan to have them registered and operate as per the City laws. We acknowledge that we haven't been able to provide public transport within the city and these operators are coming in to fill the gap of excess transport demand. However we still feel that they need to come on board and comply with all road traffic and City Council operating laws."

\section{Discussion recommendations and conclusion}

From the study, there are some factors which gave rise to the emergence of informal public transportation in Harare such as the increase in city population which in turn gave rise to increased urban transport demand,( the few formal operators not able to meet the level of demand ) Harare City council has stopped providing transport since more than 10 years ago. Economic hardship has led to most city travellers looking for cheaper transport in the form informal shuttle transport. Informal shuttle transport is convenient to passengers since they can pick and drop anywhere, sometimes manoeuvre illegally in one way roads as a way of dropping passengers faster than formal operators. The informal transport sector provides real and meaningful benefits to significant segments of populations of many third world cities. However literature and survey results also show that these informal operators in Harare usually operate without proper licensing, their vehicles are not usually serviced, the drivers are not competent enough to drive public service vehicles, for instance all public transport vehicle drivers are supposed to go through Defensive Driving Course (DDC) which these operators rarely have. The vehicles are supposed to go for roadworthy certification after every six months and get certification from vehicle inspection department (VID) before they start operating in passenger transportation and these particular ones don't go for all these mandatory inspections. Note has been taken that these small vehicles (Honda fit, Toyota Raum, Toyota Fun cargo, Toyota vitz, Toyota Wish) are unsafe in the way they ferry passengers, vehicles with sitting capacity of 5 passengers usually ferry between 7 to 9 passengers, some being even in the boot of the vehicle. A number of incidents have been registered on these informal operators as they try to flee from the police during times when police crack some hunt downs on such operators as a way of trying to sanitise the situation in the city.

The Harare City Council has two options; one is to consider registering and formalising these informal transport operators through an enabling formalisation policy in which all those involved are encouraged to come on board and get registered. The policy condition should involve training and awareness given to the operators on how and why they should operate sustainably and comply with all city by laws. Registration process should be very flexible so that these operators will not find it difficult to come on board.

The second option is for the Harare City Council to fund and acquire mass transit vehicles that will cater for urban shuttle transport to reduce transport demand. Having done that they may then impose restrictive measures against informal and illegal operators. The Harare City Council would engage both municipal and the Zimbabwe Republic Police to enforce the law against any informal transport operator to restore sanity within the city.

Conclusively the research revealed that informal shuttle transport remains a menace to the concept of sustainable transport and is not ideal.

\section{References}

Cervero, R, 2015, 'Informal transport: A global perspective', Transport Policy 14, 445-447. Coleman L (2016): Toll Roads Tip to Privatisation, www.csg.org, page 19-21.

Collier T (2014): Case Study Analysis of Mid-Size; Urban/Rural Area Toll Road Options. Technical Summary Report - Loop 49.

Davouich 2009, T., Hanrahan, K. \& Hennessy, T., 2012, Defining an institutional framework for the labour market. Factor markets, Working Paper No. 24, viewed from https://www.ceps.eu/publications/defining-institutionalframework-labour-market

Fazio, J., Hoque, M. \& Tiwari, G., 1999, 'Fatalities of heterogeneous street traffic', Transportation Research Record: Journal of the Transportation Research Board 1695

Fishbein G \& Babbar S (2015), Private Financing of Toll Roads, RMC Discussion Paper Series 117, September $29,2015$.

Freiberg, A., 2006, 'The tools of government and regulatory design', in Presentation to the Australasian Compliance Institute, Sydney. 
Government of Zimbabwe (2017) Statutory Instrument 39 of 2017 cited as the Toll Roads (Regional Trunk Road Network (Amendment) Regulations No 1.

Golub, A., 2013, 'Welfare analysis of informal transit services in Brazil and effects of regulation', PhD dissertation, Department of Civil and Environmental Engineering, University of California, Berkeley.

Gumbie M. E, Kudenga, N (2017), Rehabilitation of Zimbabwe's Surfaced Road Network, Paper presented at the Institute of Engineers, 2 October 2017, Zimbabwe

Gwilliam K.M, Shalizi Z.M (2015): Road Funds, User Charges and Taxes. World Bank. Jones J.R, Bekmez S (2011), User charges and cost recovery: The state of Idaho/ American trucking association case; Proceedings of the 36th annual conference of the Canadian Transportation Research Forum, pages 828-843.

Katz, D., 2009, 'Heterogeneous traffic mixes', viewed 3 January 2020, from http://www.donaldkatz.com/CEE6603-TermPaper-HeterogeneousTraffic.pdf

Khayesi, F., 2009, 'Informal transport and its effects in the developing world: A case study of Addis Ababa, Ethiopia', Journal of Transport Literature 8, 113-133. https://doi.org/10.1590/S2238-10312014000200006

Maini, P. \& Khan, S., 2000, 'Discharge characteristics of heterogeneous traffic at signalized intersections', in Proceedings of the Fourth International Symposium on Highway Capacity, Maui, HI, pp. 258-270.

Maunder, D.A.C. \& Mbara, T.C., 2015, The initial effects of introducing commuter omnibus services in Harare, Zimbabwe, Department of Transport, TRL 123, Transport. Research Laboratory, Crowthorne, p. 4.

Mbara, T Cynthia Celliers. Journal of Transport and Supply Chain Management; Vol 7, No 1 (2014).

Mbara, T, Kibombo, R A.S.C. Davis, and ... Chandra, D. (2015) "Socio-demographic and economic characteristics of migrant heads of households and the consequences of their migration in Fiji,

Miralles Guasch, E. Domene , 2011,Sustainable transport challenges in a suburban university: The case of the Autonomous University of Barcelona.

Praveen, P.S. \& Arasan, V.T., 2013, 'Influence of traffic mix on PCU value of vehicles under heterogeneous traffic conditions', International Journal for Traffic and Transport Engineering 3(3), 302330. https://doi.org/10.7708/ijtte.2013.3(3).07

Queiroz C, Rdzanowska B, Garbarczyk R, Audige M (2018): Road User Charges: Current Practices and Perspectives in Central and Eastern Africa. World Bank.

Rakowski, C., 2014, The informal sector debate in Latin America, State University of New York Press, New York.

Rodrigue, J-P (2017) "Transportation and the Internet", in B. Warf (ed) The SAGE Encyclopedia of the Internet, forthcoming, London: SAGE. Dablanc.

Saffarzadeh M, Rezaee-Arjroody A (2016): Cost-Benefit Analysis of Electronic Toll Collection (ETC) System in Iranian Freeways (Case Study: Tehran-Qom Freeway). PIARC International Seminar on Intelligent Transport System (ITS) In Road Network Operations. Page 2 - 12

Sclar, E., Touber, J. \& Alexander, C., 2007, Rethinking privatisation: The case of urban transportation in Nairobi, Kenya, Centre for Sustainable Urban Development,

Shittu, A.O., 2014, 'Towards quasi-formal management of paratransit in informal transport dependent cities of Nigeria', IOSR Journal of Humanities and Social Science (IOSR-JHSS) 19, 75-80.

The Herald Newspaper Issues: 10 September 2017, 17 September 2017, 21 October 2017

Yang J, Qi Qui (2015): The External Factors for the Practice of Toll Highway Systems. China - USA Business Review Volume 4 No. 7 ISSN 1537 1514, USA. Beijing Jiaotong University.

Wilkinson, P., 2008, 'Formalizing Paratransit operations in African cities: Constructing a research Agenda', in Proceedings of the 27th Southern Africa Conference

www.fitchratings.com/jsp/sector/Sector.faces accessed on 19 February 2020

www.tac-atc.ca accessed on 29 February 2020 